\title{
Correction to: Inherent Tensions and Possibilities: Behavior Analysis and Cultural Responsiveness
}

Kristin L. Miller ${ }^{1}$ - Alicia Re Cruz $^{2}$ - Shahla Ala'i-Rosales ${ }^{2}$

Published online: 17 May 2019

(C) Association for Behavior Analysis International 2019

\section{Correction to: Behavior and Social Issues \\ https://doi.org/10.1007/s42822-019-00010-1}

The captions for Figures 1 and 2 are correct, but the artwork currently above the Figure 2 caption belongs above the Figure 1 caption; and the artwork currently above the Figure 1 caption belongs above the Figure 2 caption. The original article has been corrected. 